\title{
EDUKASI LITERASI KEUANGAN KEPADA MASYARAKAT DESA MEKARSARI NARMADA
}

\author{
Susi Retna Cahyaningtyas*, Rahmi Sri Ramadani, Zuhrotul Isnaini \\ Jurusan Akuntansi - Universitas Mataram \\ srcahyaningtyas@gmail.com
}

\begin{abstract}
ABSTRAK
Literasi keuangan adalah suatu rangkaian proses atau kegiatan untuk meningkatkan pengetahuan (knowledge), keterampilan (skill) konsumen dan keyakinan (confidence) konsumen maupun masyarakat agar mereka mampu mengelola keuangan pribadi dengan lebih baik. Desa Mekarsari Narmada merupakan salah satu desa yang terdampak gempa, dimana banyak rumahrumah penduduk yang hancur. Saat ini warga sudah menerima bantuan dari pemerintah berupa uang tunai dengan jumlah yang bervariasi berdasarkan kerusakan yang menimpa setiap rumah warga. Bantuan diberikan dengan cara meminta warga untuk membuka rekening tabungan pada suatu bank. Bagi warga yang belum pernah mengenal tentang apa itu bank dan apa saja yang menjadi hak dan kewajiban sebagai penabung, merupakan hal baru. Oleh karena itu perlu ada pelaksanaan edukasi dalam rangka meningkatkan literasi keuangan kepada masyarakat. Melalui kegiatan pengabdian ini masyarakat desa Mekarsari memperoleh tambahan pengetahuan tentang literasi keuangan sehingga memiliki kemampuan dalam melakukan perencanaan keuangan dengan lebih baik, dapat menentukan produk dan layanan jasa keuangan yang sesuai dengan kebutuhan, memahami dengan benar manfaat dan risiko, mengetahui hak dan kewajiban serta meyakini bahwa produk dan layanan jasa keuangan yang dipilih dapat meningkatkan kesejahteraan masyarakat, serta terhindar dari aktivitas investasi pada instrumen keuangan yang tidak jelas.
\end{abstract}

Kata Kunci : Literasi Keuangan

\begin{abstract}
Financial literacy is a series of processes or activities to increase consumer knowledge, skills and consumer and community confidence so that they are able to better manage personal finances. Mekarsari Narmada Village is one of the villages affected by the earthquake, where many people's houses were destroyed. Currently, residents have received assistance from the government in the form of
\end{abstract}




\section{Jurnal ABDIMAS INDEPENDEN}

Vol. 1, No. 2, November 2020

cash, which varies according to the damage to each resident's house. Assistance was provided by asking residents to open savings accounts at a bank. For residents who have never known what a bank is and what are the rights and obligations of a saver, it is something new. Therefore, it is necessary to carry out education in order to increase financial literacy to the community. Through this service activity, the people of Mekarsari village gain additional knowledge about financial literacy so that they have the ability to do financial planning better, can determine financial products and services according to their needs, understand correctly the benefits and risks, know their rights and obligations and believe that The selected financial products and services can improve the welfare of the community, and avoid investing in unclear financial instruments.

Keywords: Financial Literacy

\section{PENDAHULUAN}

Literasi keuangan sangat penting untuk mendukung fungsi-fungsi ekonomi. Semakin banyak masyarakat yang tahu mengenai manfaat produk dan jasa keuangan, semakin besar transaksi keuangan yang dapat diciptakan dan pada akhirnya akan menggerakkan roda perekonomian. Peningkatan jumlah masyarakat yang mengerti produk dan jasa keuangan akan disertai dengan peningkatan penggunaan produk dan jasa keuangan sehingga menggerakkan roda perekonomian menjadi lebih cepat.

Literasi keuangan adalah suatu rangkaian proses atau kegiatan untuk meningkatkan pengetahuan (knowledge), keterampilan (skill) konsumen dan keyakinan (confidence) konsumen maupun masyarakat agar mereka mampu mengelola keuangan pribadi dengan lebih baik. Masyarakat diberikan bekal edukasi yang memadai dan mencukupi untuk mengambil keputusan keuangan dengan lebih baik, sesuai dengan apa yang mereka butuhkan dan memberikan manfaat yang lebih besar. 


\section{METODE KEGIATAN}

Metode yang digunakan untuk mencapai target luaran adalah metode partisipatif, yaitu suatu metode pembelajaran yang menempatkan peserta pengabdian sebagai pemain utama dalam setiap proses pembelajaran. Komponen pembelajaran ini mencakup dua hal yaitu pertama penyampaian materi dengan ceramah dan diskusi, serta latihan/praktik yang merupakan aplikasi dari pengetahuan yang sudah diperoleh.

\section{HASIL DAN PEMBAHASAN}

Kegiatan pengabdian dilaksanakan pada tanggal 15 Agustus 2019. Kegiatan pengabdian ini juga bekerjasama dengan lembaga investasi pasar modal yang ada di Mataram serta mahasiswa KKN dari Universitas Mataram yang ada di desa Mekarsari Narmada. Kegiatan pengabdian ini diikuti oleh 27 peserta yang berasal dari masyarakat desa tersebut, termasuk di dalamnya para perangkat desa. Tim pengabdian memberikan materi tentang pengertian literasi keuangan dan produk-produk jasa keuangan, serta jenis-jenis lembaga jasa keuangan., dengan menggunakan metode ceramah dan diskusi. Adapun rincian materi yang disampaikan yaitu pengelolaan kas, aset tetap, dan jutang serta penyampaian materi tentang jenis-jenis lembaga jasa keuangan dan produk-produk lembaga jasa keuangan, termasuk materi tentang pasar modal. Dengan pengetahuan tersebut, masyarakat akan memiliki kemampuan dalam melakukan perencanaaan keuangan dengan lebih baik, dapat menentukan produk dan layanan jasa keuangan yang sesuai dengan kebutuhan, memahami dengan benar manfaat dan risiko, mengetahui hak dan kewajiban serta meyakini bahwa produk danlayanan jasa keuangan yang dipilih dapat meningkatkan kesejahteraan masyarakat, serta terhindar dari aktivitas investasi pada instrumen keuangan yang tidak jelas. 


\section{Jurnal ABDIMAS INDEPENDEN}

Vol. 1, No. 2, November 2020
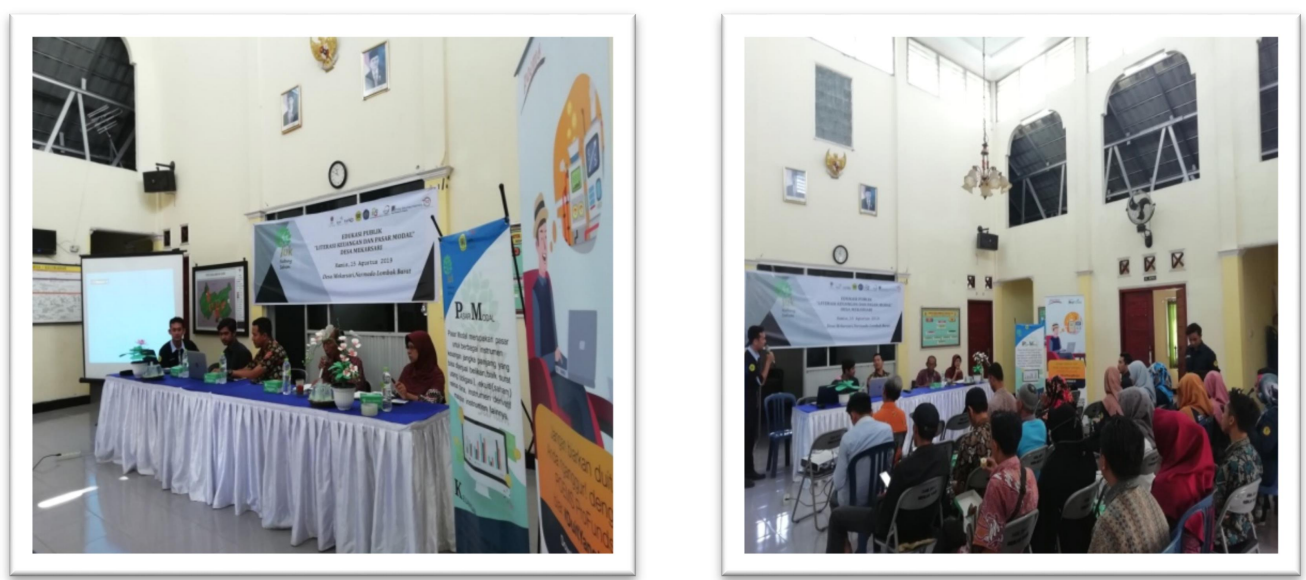

Gambar: Penyampaian Materi Oleh Tim Pengabdian

\section{KESIMPULAN DAN SARAN}

\section{Kesimpulan}

Melalui kegiatan pengabdian ini masyarakat desa Mekarsari Narmada memiliki tingkat literasi keuangan yang memadai sehingga memiliki kemampuan dalam melakukan perencanaan keuangan dengan lebih baik, dapat menentukan produk dan layanan jasa keuangan yang sesuai dengan kebutuhan, memahami dengan benar manfaat dan risiko, mengetahui hak dan kewajiban serta meyakini bahwa produk dan layanan jasa keuangan yang dipilih dapat meningkatkan kesejahteraan masyarakat, serta terhindar dari aktivitas investasi pada instrumen keuangan yang tidak jelas.

\section{Saran}

Para peserta diharapkan dapat menyebarluaskan pengetahuan yang dimiliki kepada warga lain dalam forum-forum pertemuan warga. 


\section{UCAPAN TERIMA KASIH}

Penulis mengucapkan terima kasih kepada Fakultas Ekonomi dan Bisnis seta Lembaga Pengabdian Kepada Masyarakat Universitas Mataram atas dukungan dana terhadap pengabdian ini. Tak lupa pula kami ucapkan terima kasih kepada perangkat dan masyarakat Desa Mekarsari Narmada atas partisipasinya dalam kegiatan pengabdian ini.

\section{DAFTAR PUSTAKA}

SEOJK Nomor 1/SEOJK.07/2014 tentang tata cara pelaksanaan edukasi dalaam rangka meningkatkan literasi keuangan kepada konsumen dan/atau masyarakat, http://www. ojk.go.id

POJK Nomor 76/POJK.07/2016 tentang peningkatan literasi dan inklusi keuangan di sektor jasa keuangan bagi konsumen dan/atau masyarakat, http://www. ojk.go.id

SEOJK Nomor 30/SEOJK.07/2017 tentang pelaksanaan kegiatan dalam rangka meningkatkan literasi keuangan di sektor jasa keuangan, http://www. ojk.go.id

Kasmir. 2010. Bank dan Lembaga Keuangan Lainnya. Rajawali Pers, Jakarta 